\title{
Trovar en la Alpujarra
}

\author{
Alberto del Campo Tejedor, Universidad Pablo de Olavide
}

\section{La gracia radica en llegar al límite, en asomarse al vacío, donde las palabras ya no sirven}

Decir que la naturaleza lúdico-competitiva, el registro burlesco y el contexto ritual-festivo son algunas de las características de la poesía improvisada que los alpujarreños conocen como trovo, no es más que glosar con palabras del mundo del que se habla lo que ellos mismos consideran imprescindible en una buena velá de trovo: el pique, las pullas de los troveros o trovadores. Por eso llaman porfía de trovo al intercambio de quintillas que mantienen generalmente dos improvisadores, a dúo y debate (a porfía, dicen), bien cantás al ritmo del fandango que marcan el violín, la guitarra, la bandurria y el laúd, bien sin acompañamiento musical, a lo que los alpujarreños granadinos otorgan un mérito menor, el trovo hablao, especialidad de los improvisadores del Campo de Dalías almeriense. Es el trovo para los buenos fiesteros, por encima de todo, un juego, especialmente cuando alcanza el grado de la picaílla. Para llevarse el gato al agua, el trovero ha de superar al rival y ello no viene dado tanto por la perfecta ejecución literario-musical (ajustarse a la música, lo que llaman entrar con la subía y arreglar los instrumentos, el verso octosílabo y la rima consonante de las quintillas o décimas), sino sobre todo por el ingenio y la comicidad de unos versos que -sin salirse del tema, es decir, discurriendo con cada copla sobre el asunto, el objeto de la controversiabuscan sorprender y agitar a la concurrencia, para levantar el ole y desatar la carcajada. Y es que, para que se produzca la comunicación feliz en una velá de trovo, es necesario el que escucha, imprescindible partícipe de la reunión, al que los alpujarreños consideran tan fiestero como el que canta e improvisa.

El trovo deseable se recrea en cada lance. Gusta a veces el virtuosismo de una rima imposible, o el conceptismo de la imagen rebuscada, pero más aún el hallazgo inesperado en una recombinación audaz de material cercano a la memoria que permita la instantánea comunicación con todo el que participa en la velada, algo así como decir lo de siempre (lo que es común, lo conocido por todos, en lo que todo el mundo está de acuerdo, lo que a uno le gustaría decir si tuviera dotes para decirlo poéticamente) de manera imaginativa, ingeniosa, pasándolo por el cedazo de la comicidad. La rapidez, la dificultad, pero más aún el ingenio satírico es la sal y la pimienta de un trovo bien hecho, especialmente cuando es usado para motejar al rival y sentarle en la silla con una bofetada poética, dejando así en ridículo la postura defendida por éste. Al fin y al cabo, enfundándose el traje trovadoresco, el 
( Templando en la calle, antes de la velá / Foto: ISABEL MUNuERA
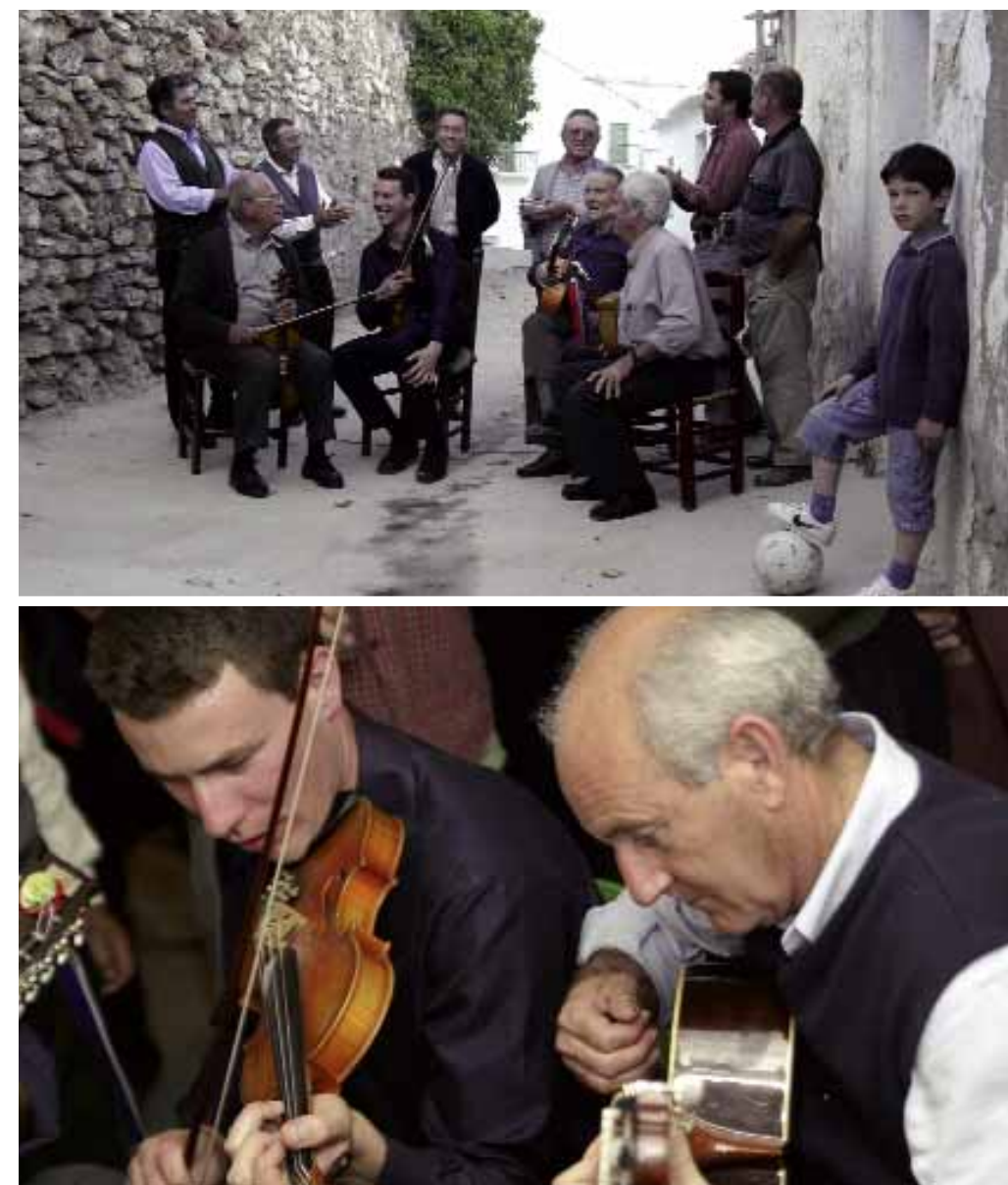

.

$$
1 \text { - }
$$

(- La velá de trovo en la bodega: comensalidad / Foto: ISABEL MUNUERA
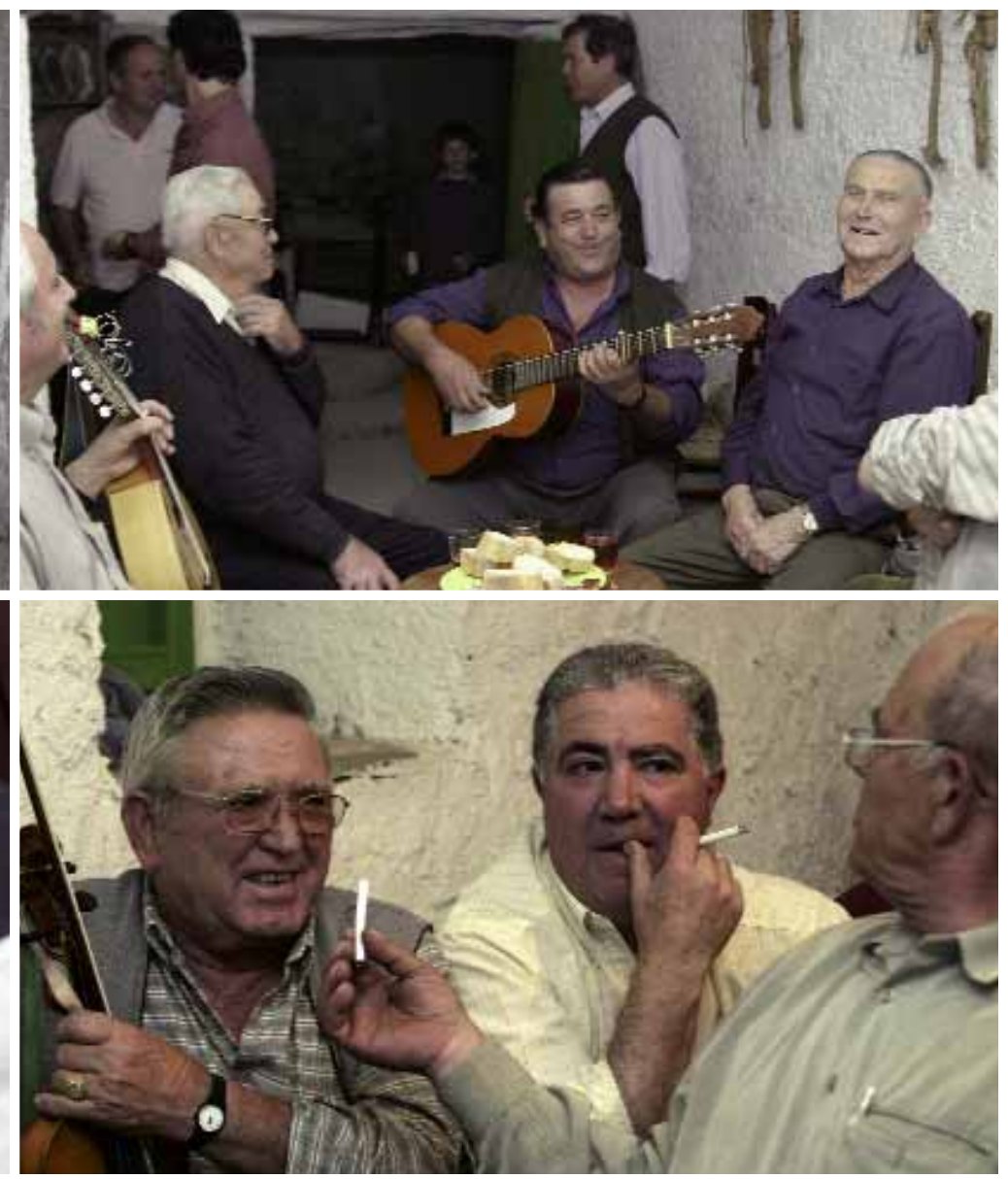

๑ La música: Vicente Fernández al violín, Constante Berenguer a la guitarra / FOTO: ISABEL MUNUERA

(1) Entre revezo y revezo de trovo / Foto: ISABEL MUnUeRA 


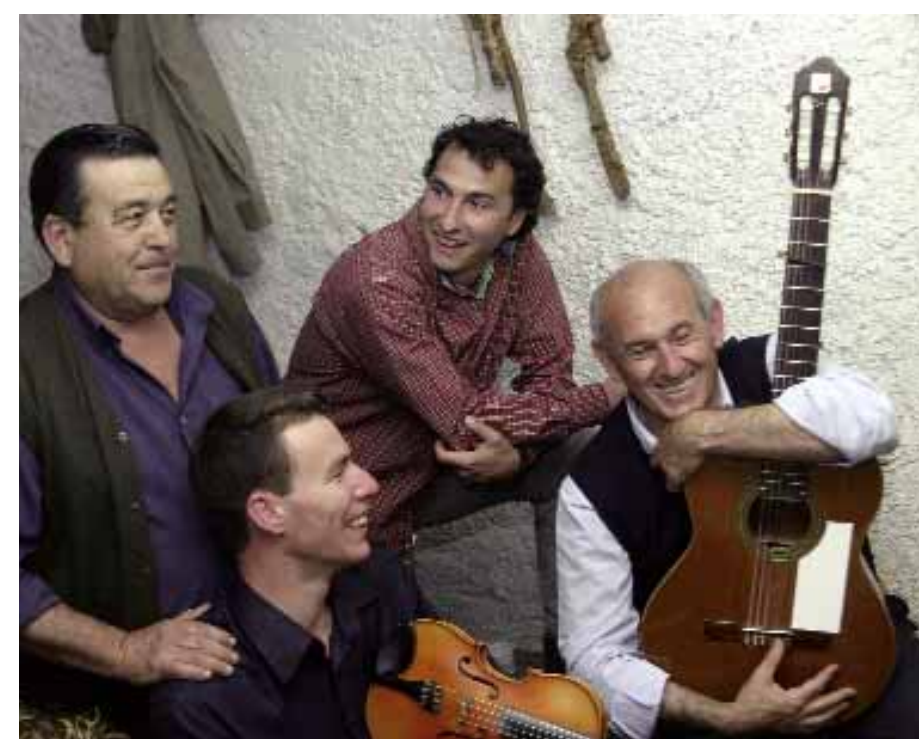

(1) La pulla y la burla / Foto: ISABel Munuera

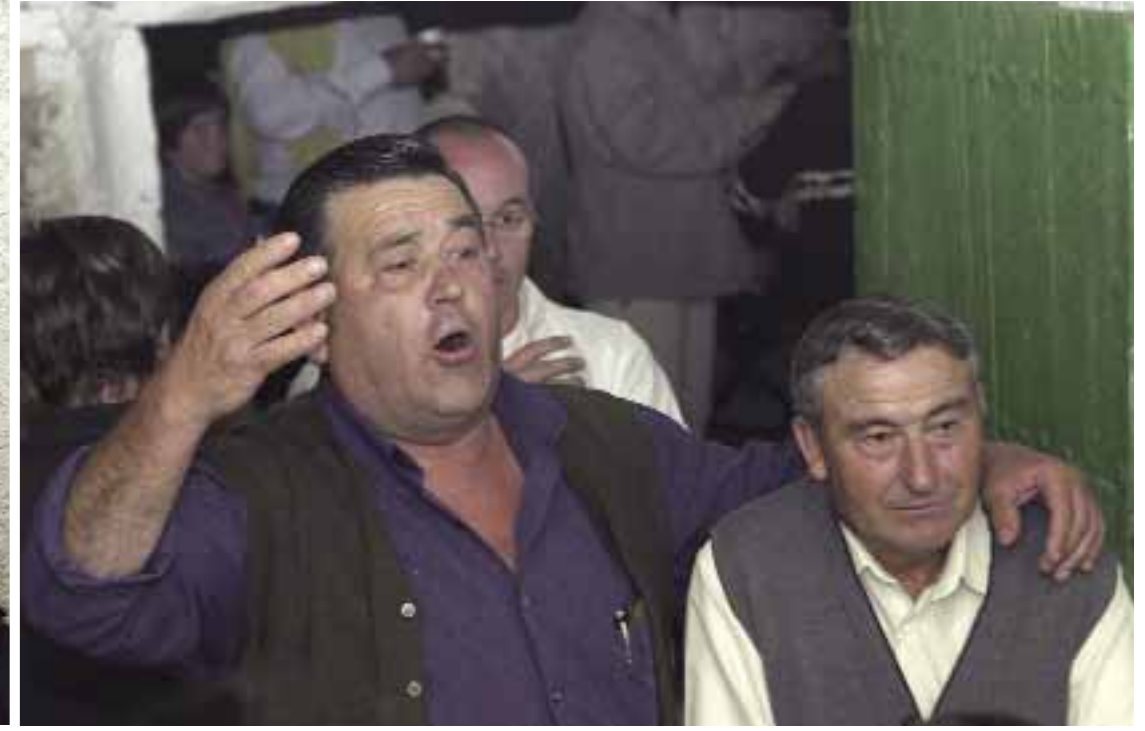

(1) La despedía. Paco Megías y Manuel el de la Magaña / Foto: Isabel Munuera y reír juntos, precisamente con aquellos con los que se comparten fatigas. De ahí el echar un revezo de trovo, que remite a la vez a la acción instrumental y la expresiva, no sólo un acto estético, sino también moral, un juego extra-ordinario, necesario contrapunto al trabajo ordinario -el echar un revezo en el campo-, rato de faena que se complementa -bajo la lógica de la inversión- con el rato de fiesta.

Naturalmente el trovo no es sólo juego satírico, ni los mimbres de sus versos están hechos sólo de cortante esparto. El trovo es casi tantas cosas como diferentes momentos en que surge: planto funerario o enhorabuena epitalámico, tan pronto agasajo por la cosecha compartida, como conjuro frente a la enfermedad y la mala suerte. Tampoco es privativo de la Alpujarra. Como lenguaje ritual para solucionar disputas mediante el humor que señala pero no excluye, para decir las cosas sin mentarlas, o simplemente para aliviar la rutina y el prosaico tedio, es tan universal, como específicas son las maneras andaluzas, granaínas y almerienses, alpujarreñas, jde los cortijeros de la Contraviesa o de la gente (de) la playal, que otorgan al trovo alpujarreño una singularidad dentro de un género panhispánico repentista, que es posible rastrear desde el primero de todos los poetas, Homero. En contacto con otras tradiciones improvisatorias, en los diferentes encuentros y festivales, los troveros han comprendido que este lenguaje desinhibido, que juega a sacarle los colores a la corrección y voltear la realidad más asumida, es su principal originalidad y aun su más fiel arma en unos combates que algunos lidiarán tanto mejor cuanto más bufos. El lugar tradicionalmente subalterno de los cortijeros (en oposición a los habitantes de pueblos y villas), su condición campesina, minifundista, autosuficiente pero necesitada del otro, en donde los frecuentes conflictos han de ser resueltos con instancias sancionadoras informales como las que proporcionan estas controversias humorísticas, probablemente han permitido la pervivencia de este arte en el campo, en los pequeños núcleos, más que en ningún otro sitio. En los dos últimos siglos, el progreso y el estado de bienestar -acaso más que un proceso consciente de Ilustración y una cruzada contra el mal gusto- han arrinconado esta vis comica, que durante siglos ha servido para sobrellevar la vida en los márgenes del proceso de civilización. El relativo auge de festivales y actuaciones sobre el tablao promovidos institucionalmente se enfrenta, como todo movimiento folclórico, al mito ilustrado de la cultura universal. Y lo hace con el arsenal romántico que valora lo rústico, lo espontáneo, lo irracional, pero topan irremediablemente con el encorsetamiento que produce un contexto escénico más propicio para actuar -en el sentido más teatral de la palabra- que para dejarse llevar por el torbeIlino poético y ser arrastrado a la otra cara del mundo. Reducido a un modelo estético que no comprende unos juegos del lenguaje gestados en el mundo en el que se habla para sonrojar, los festivales suelen promover una poesía que lime las asperezas del terruño, las inconveniencias del descaro y olvide -en el enésimo intento de redención y civilización del Pueblo- a Dionisos, Príapo y a todo lo que Nietszche veía como la animalidad mediterránea que acabaría sucumbiendo al Estado. El festival puede propiciar la difusión de la rima improvisada pero más rara vez la vivencia de una fiesta de trovo, en la que cada quintilla más que una manera bella (o diferente) de decir las cosas, es la manera buena, en el múltiple sentido de utilidad práctica, de deseabilidad moral y goce desenfadado, elementos que convergen en lo que los alpujarreños Ilaman una buena copla.

El trovo es más que burla carnavalesca, los troveros más que histriones. Sí, pero esa faceta, la más extraordinaria y tradicional -en el sentido 
(-) Fin de fiesta / Foto: Isabel Munuera

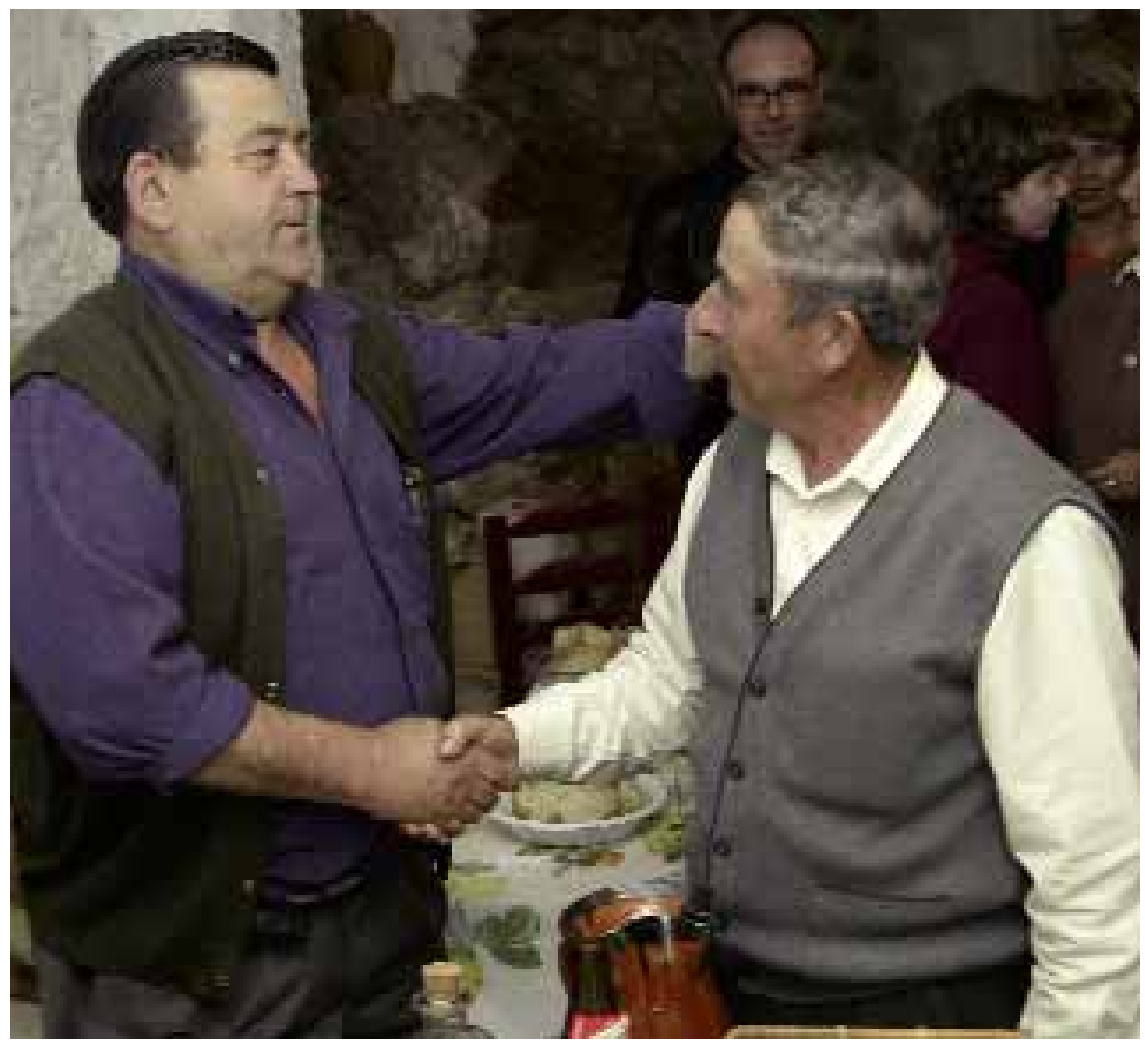

que le dan los propios alpujarreños-, es acaso

Nota

también la más incomprendida y amenazada. 2007 fue un año funesto para el trovo. En poco más de tres meses morían Andrés Linares, el único trovero en toda la tradición repentística hispánica, hasta donde conozco, capaz de improvisar al mismo tiempo y con la misma aparente facilidad con que su violín llevaba la voz cantante durante toda la fiesta, y Miguel García Candiota, el maestro indiscutible de esta manera de hacer cosas con palabras. En la velada, en el cortijo, en la bodega, en la reunión de amigos y familiares en torno a la mesa y el vino, donde se pueden decir las cosas a la cara si se dice con eso que los andaluces llaman en algunos sitios arte o guasa y en otros, como la Alpujarra, gracia; ahí transmitieron ellos su saber con el mismo tempo y gusto de los artesanos, a los escasos troveros jóvenes que aún hacen de las suyas en ciertas fiestas al sur de Granada, donde el guiño socarrón aún vincula a los hombres con otras verdades. Descansen en paz.

La bibliografía sobre el trovo alpujarreño, y aun sobre el repentismo en general, ha aumentado considerablemente en la última década. La mayoría de las referencias puede consultarse en Del Campo, A. Trovadores de Repente. Uno etnografía de la tradición burlesca en los improvisadores de la Alpujarra (Salamanca: Miletnio, Diputación de Salamanca, 2006). Están editadas igualmente algunas de las controversias troveras en las sucesivas grabaciones del Festival de Música Tradicional de la Alpujarra, que se celebra anualmente en un pueblo diferente de la comarca, el segundo fin de semana de agosto. El escaso material videográfico se reduce a algún corto documental producido por Canal2Andalucía. Recientemente troveros, aficionados y estudiosos han creado una asociación de defensa y desarrollo del trovo que lleva por nombre al más grande de todos los troveros: Miguel García Candiota. Paralelamente en la pequeña localidad de Murtas, a la sombra del Cerrajón, el pico más alto de la Contraviesa, se ultima una casa-museo del trovo, después de alguna experiencia desigual para crear una escuela de trovo. Además del Festival de Música Tradicional de la Alpujarra y otros festivales como el de Las Norias (El Ejido, Almería), muchos pueblos alpujarreños (Albondón, Albuñol, Cádiar, etc.) incluyen la actuación de troveros en el escenario durante sus fiestas patronales. Con el objeto de romper el reducido círculo de las tradicionales fiestas cortijeras y promover el contacto estrecho y la complicidad entre troveros y los que no siempre tienen ocasión de vivir una velada de trovo, respetando las imprescindibles condiciones de cercanía, comensalidad y tempo festivo, se viene celebrando en Murtas el Día del Trovo Alpujarreño 